\title{
Stray cats in Auckland, New Zealand: Discovering geographic information for exploratory spatial analysis
}

\author{
Glenn D. Aguilar, Mark J. Farnworth
}

\begin{abstract}
Stray cats are a common feature of urban landscapes and are associated with issues of animal welfare and negative environmental impacts. Management, planning and decision-making require readily accessible information on stray cats. However, much of the existing data is not immediately useful for a geographic information system (GIS) in terms of format, content and explicit location information. Spreadsheets we obtained from a single large shelter in the Auckland region. They contained records of stray cat pickups and admissions for an entire year $(n=8573)$ of which $56.4 \%(n=4834)$ contained data that could be processed to derive relevant spatial information. The resulting data consisted of identified roads and areas of Auckland where the stray cats were found. Published census databases and shapefiles were matched with the data to build a GIS of stray cats. Global and local regression analysis was employed to discover spatial distribution characteristics including the identification of areas with relatively high and low concentrations of stray cats and to explore relationships between socioeconomic condition and stray cat density. Significant clustering is more evident in South Auckland than elsewhere in the region. Specific geographical information is valuable, not only for understanding population dynamics of stray cats, but also to allow spatial and temporal targeting of resources to minimise their impact and promote responsible ownership.
\end{abstract}

\section{Introduction}

Much of the available information on stray cats in Auckland is collected incidentally or during handling and response by welfare charities. Such collected data are not ideally suited for GIS as they do not explicitly contain the exact coordinates or locations. However, they may still be valuable when converted into spatially relevant information. This is even more useful when the data contain location names implying a problem domain that is inherently geographic in nature and the data records are of sufficient number for appropriate quantitative or statistical analysis (Ahlqvist, Ban, Cressie, \& Shaw, 2010; Tao \& Jiaqiu, 2008; Whyte, 2011; Zhang, Wong, So, \& Lin, 2011). Manual or computer aided processes are required to transform available data into suitable formats for GIS. If properly processed, transformed and analysed, significant enhancements in presentation, opportunities for analysis and useful information may result from such conversions (Flocks, 2004; Jung \& Elwood, 2010; Oberlies et al., 2009).

As companion animals (pets), cats are valued members of households and undoubtedly provide significant benefits to their owners (Staats,Wallace, \& Anderson, 2008) and therefore society as a whole. Stray cats, on the other hand, are associated with poor animal welfare, threats to wildlife and protected habitats as well as health and social concerns (Levinthal, 2010; Morgan et al., 2009; Simking, Wongnakphet, Stich, \& Jittapalapong, 2010). The freeroaming cat population is recognized as a significant issue in New Zealand (Farnworth, Campbell, \& Adams, 2011), especially since cats are an introduced mammalian predator to which New Zealand's indigenous avifauna are poorly adapted. As a result their impact can be devastating even in low numbers (e.g. King,1984, p. 73).Work on modelling of domestic cat predation in Dunedin (van Heezik, Smyth, Adams, \& Gordon, 2010) shows that urban birds are affected by cat predation at levels which affect population persistence. Further, the study suggested urban areas act as sinks for bird populations with the surrounding natural areas acting as source habitats. Sections of Auckland contain significant areas of forest and bush habitat (e.g. the Waitakere and Hunua ranges) which may perform similar source functions with nearby urban sections acting as sinks. The high priority that the country places on environmental protection and conservation have resulted in feral (and to some extent stray) cats being recognized as pests (Farnworth, Dye, \& Keown, 2010) and their impact carefully assessed for proper management (Morgan et al., 2009).

Cats are also New Zealand's most popular companion animal comprising an estimated 57\% of the total number of pets (excluding fish) (Argante, 2008; Kerridge, 2000). The manner in which the human population manage and care for cats is instrumental in mitigating their impact upon local ecology. Cats, when deprived of consistent human care, naturally stray because of their nutritional and 
reproductive requirements (Say \& Pontier, 2004). A major component of cat population management is, therefore, limitation of the breeding population. This is especially important since cats are able to transition to a feral state within a single generation (Bradshaw, Horsfield, Allen, \& Robinson, 1999) and therefore may have a concomitantly increased impact upon local ecology. In the absence of lethal control, sterilization (amongst other strategies) is paramount to achieving a reduction in the viable population (Calver, Grayson, Lilith, \& Dickman, 2011) and early (pre-pubertal) sterilization allows prevention of pregnancy before it is possible (Aronsohn \& Fagella, 1993) eliminating the future impacts of unborn cats. New Zealand's companion cat population has a relatively high rate of sterilization (91.7\%: McKay, Farnworth, \& Waran, 2009; 87\%: Farnworth, Campbell, \& Adams, 2010) when compared to other similar countries in the literature (e.g. Ireland (76\%) Downes, Canty, \& More, 2009; Italy (43\%), Slater et al., 2008), however there is still room to improve as little is known about how many free-roaming cats are sterilized. Similarly education about cat care and sterilization are critical for owner compliance (Slater et al., 2008). Given the limited funds available to promote sterilization and owner education there is a need to establish readily accessible information on the nature of stray cats for supporting relevant planning, management and decision-making efforts. In the literature GIS has been explicitly used to determine the influence of climate and other environment factors on the distribution of feline borne infections in Bangkok (Simking et al., 2010), endangered cat species (Marino et al., 2011; Wilting et al., 2010) and impact of inside/outside domestic cats on an urban forest reserve Kays and DeWan (2004). Geospatial techniques were also used in determining the relationship between cat deaths, human deaths and socioeconomic indicators reflecting deprivation across Boston neighbourhoods (Patronek, 2010). More detailed GIS information which is area specific, may aid cat management and welfare aims.

Worldwide, stray cats vary greatly in density from 1 to 2000/ $\mathrm{km}^{2}$ (Liberg, Sandell, Pontier, \& Natoli, 2000). Density estimates in New Zealand range from 1 to $7 / \mathrm{km}^{2}$ in farms and rural areas (Fitzgerald \& Karl, 1986; Jones, 1977, Jones \& Coman, 1982; Langham, 1992; Langham \& Porter, 1991). The significant variance in reported density means that estimates from other countries or cities are not reliable measures for local decision-making. With the availability of data from animal welfare organizations there was an opportunity to establish a geographic information system (GIS) on stray cats. Aside from being a necessary and important first step in building sufficient knowledge, the resulting GIS was viewed as an important tool or approach to address similar problems in other New Zealand areas with considerable stray cat populations. This work sought to develop an approach converting non-ideal data into a GIS format that allowed for the presentation of stray cat density in a large urban environment, a description of temporal distribution characteristics and spatial analysis including global and local clustering as well as the exploration of relationships with socioeconomic factors.

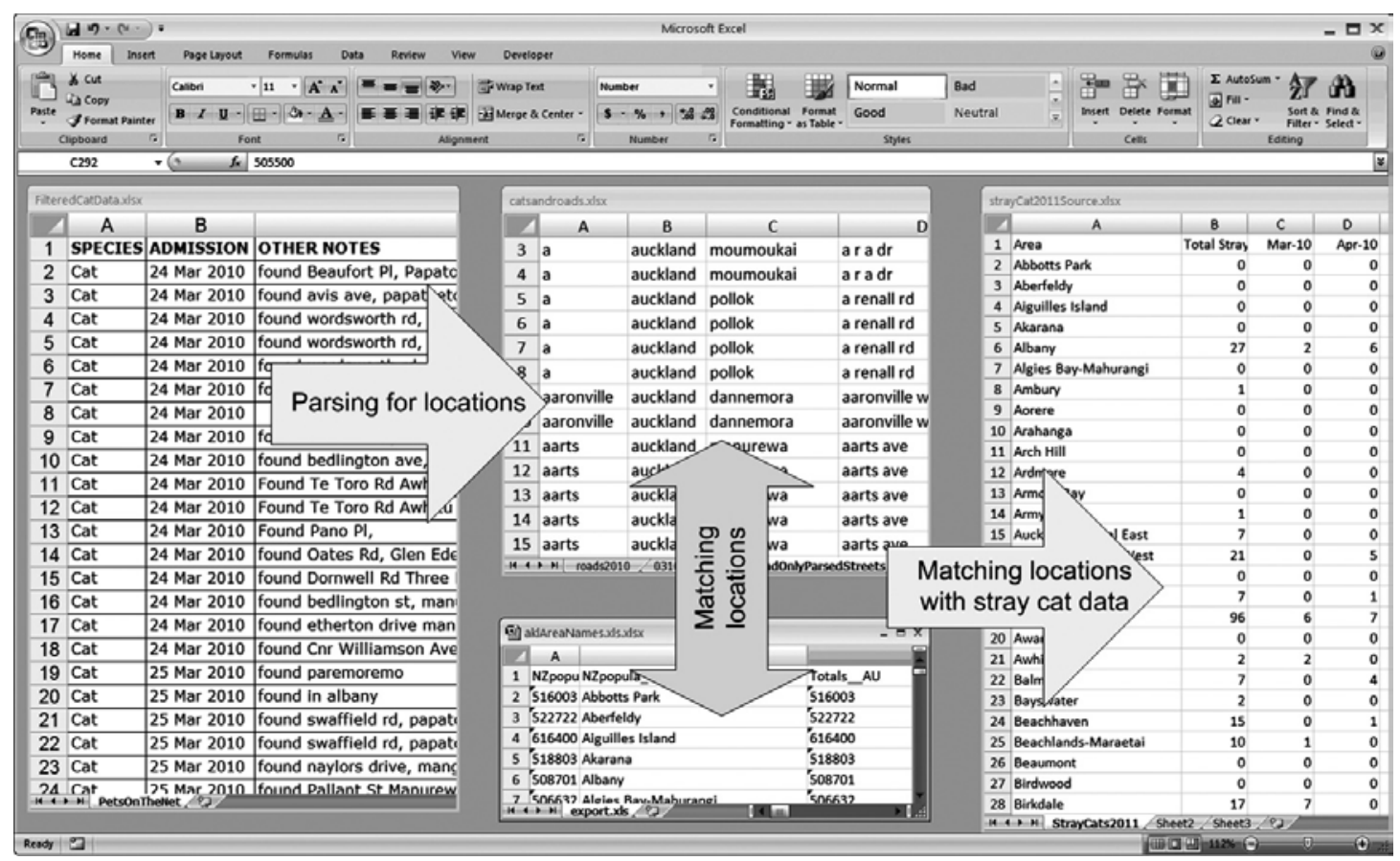

Fig. 1. Spreadsheet data source processing for stray cats. 


\section{Methods}

Data acquisition from ordinary sources

An Excel spreadsheet list of stray cats recorded over a one year period from March 2010 to March 2011 was obtained from the Auckland Society for the Prevention of Cruelty to Animals (SPCA). The data consisted of stray cats picked up by the SPCA or brought to their offices by concerned individuals. Pickups are mostly based on reports of stray cat presence by the public. The record also contains cats caught in traps set at different locations as well as those deposited at several veterinary clinics and picked up by the SPCA. Stray cats are differentiated from registered pets by checking for the presence of identification microchips or other forms of owner ID.

In its initial form, the spreadsheet file contained a column of dates and another column with entries describing the area or street found and in some cases, conditions of the animal upon pickup. Hence, the sources of geoinformation in the data were in an incidental description column consisting of a text string that may or may not contain the location. The spreadsheet was processed by parsing the strings in the description column into individual words. Each word was matched with corresponding fields in the reference area and roads database (the New Zealand 2006 census database for area names and New Zealand road database for street names) to determine the location of each record or row (Fig. 1). A manual scan determined which records had obvious errors (e.g. spelling mistakes) or redundancy and corrections were made by replacing the text automatically using the find and replace function of the spreadsheet software.

Once most of the errors were corrected, a merger of street records in both the source database and the reference databases was necessary because some street names were not unique to an area unit. The merged street and area records were then matched the reference database to verify that the instance of the stray cat record belonged to that area. Some of the area descriptions entered in the source databases were not the official names in the Census database or in many instances, the stray cat database general areas were further subdivided (e.g. into North and South or East and West). It was therefore, necessary to address these differences. This required the merging of Census areas to match the source data resulting in a reduction in the total number of area units and an increase in the total area of some area units.

The resulting corrected data were then joined with the corresponding roads and streets shapefiles in the GIS (ArcGIS) software. Two layers resulted from the geocoding process: 1) a polygon layer for the areas with stray cats and 2) a polyline layer for roads with stray cats. The polygon layer was used to determine densities in terms of stray cats per unit area. While the resulting density was based on an aggregation of cat counts for a period of time, it was a valuable comparative measure useful for subsequent spatial analysis. With data on pickup dates available, it was also possible to show temporal characteristics of the counts over the period covered. As official Census units of the Auckland region, it was more practical to use polygons as the basis of the spatial analysis conducted. Area based spatial analysis was employed in a variety of studies including historical analysis (Zhang et al., 2011), dengue fever risk (Khormi \& Kumar, 2011) and landcover relationships with ecosystems (Shaker, Craciun, \& Gradinaru, 2010). Road information on the other hand, presents another reference to confirm stray cat pickup locations at respective areas.

\section{Global and local clustering}

The nature of the spatial distribution of stray cat densities was determined using Moran's global index I, a measure of spatial autocorrelation that quantifies the degree of clustering or uniform distribution overall (Moran, 1948, 1950). A positive index represents clustering with areas near each other having a small difference in the variable or parameter used; a negative index indicates a dispersed pattern while a value of the index near 0 implies a random distribution. Inverse distance squared weighing was used to measure spatial relationships with the influence of each area unit decreasing exponentially with distance. This also means that the greatest weight was assigned to the closest neighbouring area unit. The method used to determine the distance between area units was the Euclidean distance measurement method or a straight line distance calculation. Another parameter set was the distance threshold used to determine the limits of calculating the weighting. The distance required for further analysis such as local regression is indicated by the maximum z-score therefore it is necessary to calculate global Moran's $I$ for a range of distances. 
While the global Moran's $I$ is useful for the overall area, it does not identify where the clustering takes place. To determine the local neighbourhoods where groups of areas may exhibit clustering, the Anselin's Local Moran's I was utilized (Anselin, 1995). Anselin’s Local Moran's I breaks down the global Moran's I into contributions for each area unit by measuring similarities or dissimilarities in the parameter's values with the surrounding area units. Inverse weighted distance squared, the Euclidean distance measurement and the distance threshold with maximum z-score determined in the global Moran's I calculation were employed as options in the analysis. Groupings of positive I values with significant z-scores in close proximity provide evidence of clustering while groupings of negative spatial autocorrelation indices provides an argument for a lack of clustering. This work follows a minimum of six significant positive indices in close proximity as evidence of clustering, similar to the work of Schuurman, Peters, and Oliver (2009). For a convenient visualization or clustering using Anselin's Local Moran's I, areas with statistically significant (0.05) indices are classified using the local and global means (local mean is the average stray cat density using the area's neighbourhood while the global mean is the overall average). We used the symbols $\mathrm{HH}$ for areas with local means higher than the global mean; LL for areas with local means lower than the global mean; HL for areas with values higher than the local mean and; LH for areas with values lower than the local mean (Anselin, Syabri, \& Youngihn, 2006; Mitchell, 2005).

\section{Table 1}

Stray cats recorded for the period March 2010 to March 2011 for Auckland area units for the top 20 areas.

\begin{tabular}{llll}
\hline Area & $\begin{array}{l}\text { Density } \\
(\text { count/km²) }\end{array}$ & Count & City \\
\hline Manurewa & 50.41 & 449 & Manukau City \\
Papakura & 35.29 & 254 & Papakura District \\
Mangere & 32.64 & 497 & Manukau City \\
New Lynn & 29.54 & 40 & Waitakere City \\
Papatoetoe & 29.06 & 275 & Manukau City \\
Mt Roskill & 27.29 & 121 & Auckland City \\
Clendon & 27.14 & 49 & Manukau City \\
Panmure & 26.39 & 42 & Auckland City \\
Mt Albert & 25.64 & 50 & Auckland City \\
Clover Park & 22.81 & 21 & Manukau City \\
Otahuhu & 22.80 & 109 & Manukau City \\
Otara & 22.21 & 129 & Manukau City \\
Onehunga & 20.87 & 103 & Auckland City \\
Glen Eden & 19.93 & 50 & Waitakere City \\
Weymouth & 19.42 & 55 & Manukau City \\
Flat Bush & 17.16 & 49 & Manukau City \\
Howick & 17.16 & 45 & Manukau City \\
Glenfield & 17.02 & 58 & North Shore City \\
Bucklands Beach & 16.29 & 15 & Manukau City \\
Avondale & 14.99 & 72 & Auckland City
\end{tabular}

Relationship with social factors

Stray cats depend on anthropogenic food sources and may also be former domestic pets with strong dependence on humans; hence it was deemed valuable to investigate relationships between social factors and the presence of stray cats in the different areas (Alessa, Kliskey, \& Brown, 2008, Levinthal, 2010). The New Zealand Deprivation Index or NZDep2006 was used as the determining variable because the data reflects social conditions of the entire country and the data is at the mesh block level, the smallest official census polygons that that make up the polygon or area used in geocoding. NZDep2006 is available in two forms, an ordinal scale of 1-10 (with 10 representing the highest level of deprivation and 1 the least) and a continuous score which scaled to have a mean of 1000 index points and standard deviation of 100 index points. The NZDep2006 ordinal 10 point scale index is derived from this continuous score. Based on the 2006 census the parameters are referred to as "dimensions of deprivation" and include as variables (in order of decreasing weight), home ownership, employment status, age, qualifications (New Zealand term for the level of education), living space, access to communication and access to a car (Salmond, Crampton, King, \& Waldegrave, 2006). In this study, because the each area unit is an aggregation of NZDep2006 mesh block units, population 
weighted scores of the larger enclosing areas were calculated as recommended by Salmond, Crampton, and Atkinson (2007).

The traditional ordinary least squares regression (OLS) was used to initially provide an idea of existing relationships between stray cat density and the NZDep2006 scores. When results of global regression analysis such as OLS insufficiently describe the spatial relationships or when spatial autocorrelation (inherent in geographic data with nearby features more likely to be similar than farther ones hence violating assumed independence in error distribution) is present, local regression using geographically weighted regression (GWR) is normally employed (Fotheringham, Brunsdon, \& Charlton, 2002; Legendre, 1993). GWR addresses the assumption in traditional statistics that the relationship is spatially constant with variables remaining constant over spatial distances (Dark, 2004; Mitchell, 2005; Shi et al., 2006). GWR includes spatial influences by deriving the local regression of each location and calibrating parameters using distance weighted neighbourhood observations. GWR produces a set of estimates, local standard errors, measures of significance, influence statistics, condition numbers and local $r^{2}$ values. The distance weight is usually defined by a decay function dependent on the distance between locations and a bandwidth that determines the decay value intervals (Wang, Ni, \& Tenhunen, 2005). The Akaike Information Content (AIC) parameter that allows comparisons of the results of global regression (OLS) was also calculated. Better modelling is indicated when GWR has less AIC value than OLS and the magnitude of the difference is more than 3 (Zhang et al., 2011). In addition, residuals of both OLS and GWR results were analysed using global Moran's I to test for spatial autocorrelation. If the results of global Moran's I on the residuals show significant p-values, there is spatial autocorrelation present and the results of the analysis may be unreliable (Brunsdon, Fotheringham, \& Charlton, 1998; Fotheringham et al., 2002; Gao \& Li, 2010).

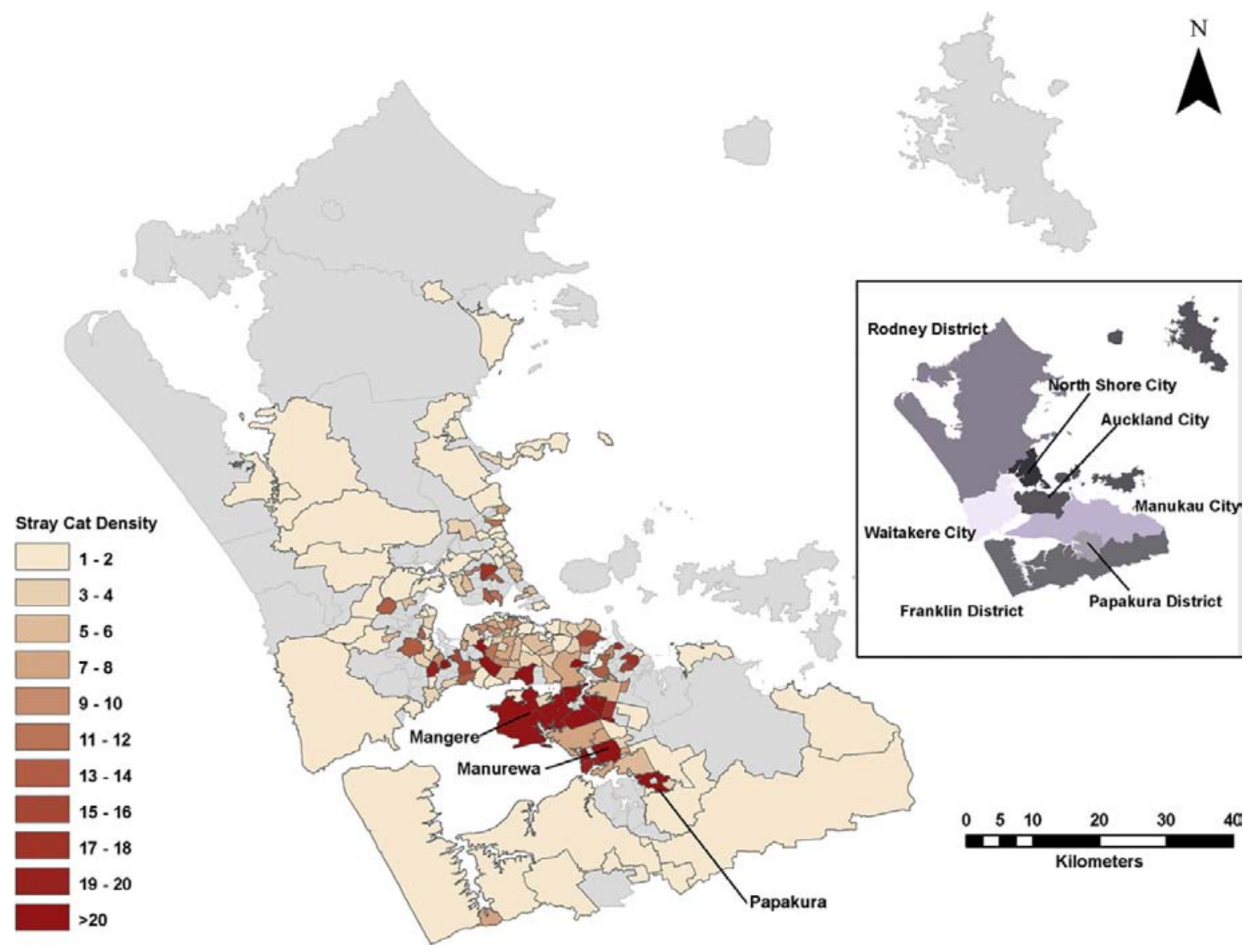

Fig. 2. Distribution of stray cats in Auckland, New Zealand from data recorded March 2010-March 2011 by SPCA. 


\section{Results and discussion}

Processed stray cat data

The initial parsing with Excel resulted in location data for 4834 out of 8573 records in the data (56.4\%). Further data processing was done through manual verification of the entire dataset and correcting obvious errors. Majority of the errors in the data consisted of incorrectly entered street types, street names and area names. Examples of entry corrections and the number of corrections made include "rd,” to "rd” (693 corrections), “place,” to “pl” (332), “road,” to “rd” (311), "ave,” to “ave” (285) and "street," to "st" (258). Once the streets were corrected, area units were identified and matched with the official databases using the lookup function of the spreadsheet software to generate both the areas and streets with stray cat database.

Error correction resulted in 4140 geocoded records with matching area units out of a total 4447 records (93.10\%). The remaining records without location data consist of entries that indicate possibly wild or feral cats, stray cats caught in traps and other entries with only the date entered. The final table shows that out of 307 area units, 159 had stray cat pickups or 51.79\% of official Auckland area units had stray cat presence. In the areas where they were found, the average for the period recorded was 14.63 stray cat counts per area. Overall, density is 1.67 stray cats per square kilometre using only the areas where the stray cats were found. Processing the roads data resulted in 1973 out of 4447 records (44.37\%) with identified matching road locations. For the entire Auckland area, 8.42\% (1043 out of 12,392) of roads had stray cats picked up for the period.

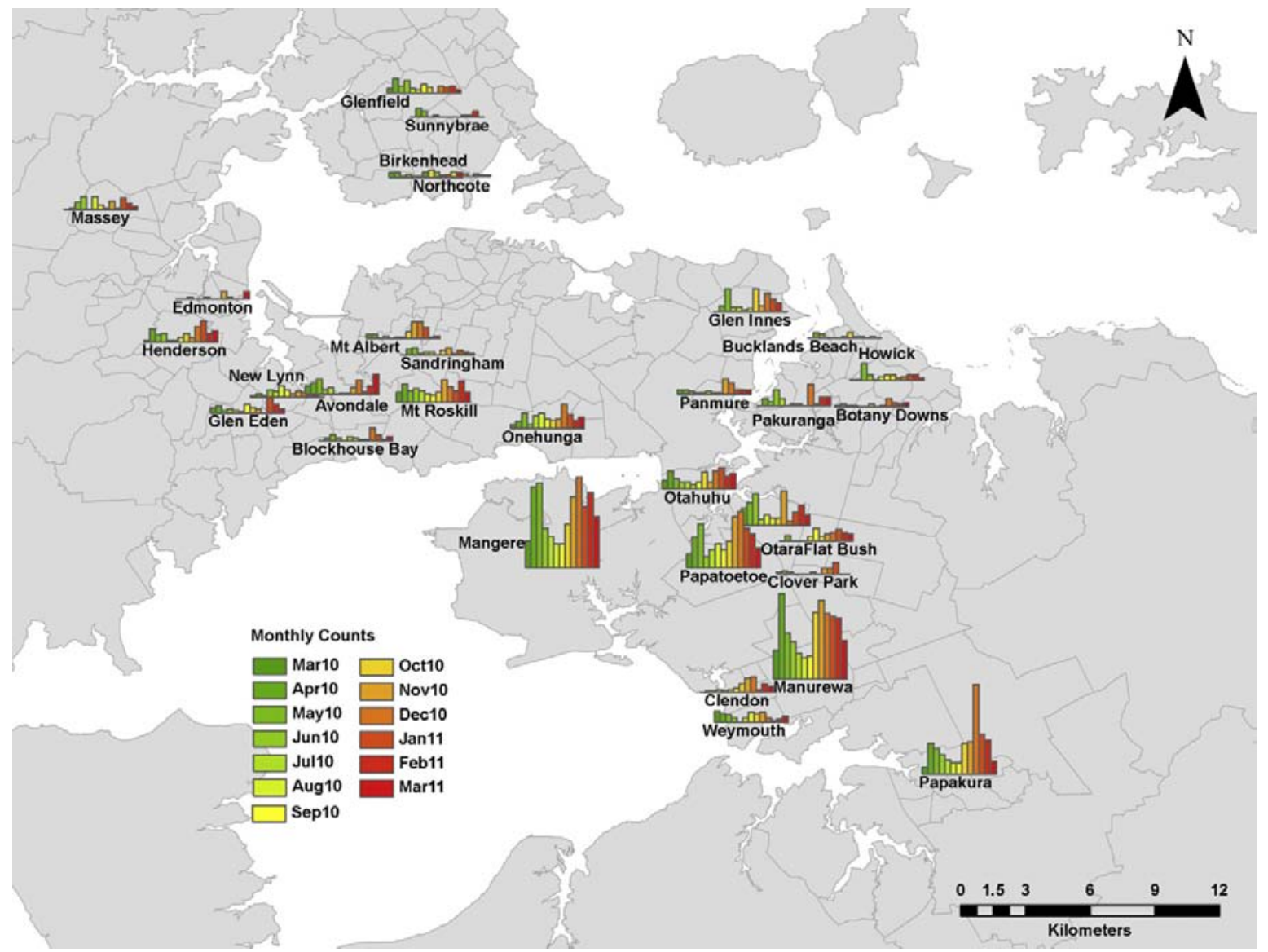

Fig. 3. Monthly trend of stray cat count densities for areas where total stray density is greater than 10 stray cats/km2.

\section{Stray cat spatial distribution}

The aggregated stray cat density for the period per square kilometre is found highest in the South Auckland area of Manurewa with 50.41 stray cats per square kilometre followed by Papakura with 35.29 and Mangere with 32.64. The highest number of cat counts was recorded in Mangere with 497, Manurewa with 449 and Papatoetoe with 275 (Table 1). In terms of Auckland regions, Southern Auckland including the former Manukau City (all Auckland Cities and Districts were merged in 
November 2010 to form an Auckland “Supercity”) and Papakura District has the highest density and most number of stray cats recorded for the period (Table 1 and Fig. 2).

\section{Monthly trend of stray cat counts}

Since the processed data contained monthly stray cat counts, a map showing the top areas with more than 10 stray cats $/ \mathrm{km}^{2}$ was produced (Fig. 4). Two peaks of stray cat records show consistently for all of the areas with one peak during the summer and another peak 3-4 months after. The pattern indicates a well defined seasonal distribution similar to results of a study of stray cat admissions in Australia (Marston \& Bennet, 2009).

Global and local regression results

Global Moran's I indicates significant clustering of stray cat density or areas with similar levels of stray cat densities are found in close proximity rather than randomly distributed or dispersed throughout the Auckland region. The maximum z-score was found at the $22 \mathrm{~km}$ distance threshold ( $I=$ 0.085; z-score $=2.292$; $p$-value $=0.021$ ) when the global Moran's $I$ was calculated for distances starting at $1 \mathrm{~km}$ (with $1 \mathrm{~km}$ intervals). The resulting distance threshold was subsequently used for local clustering analysis.

Anselin's Local Moran's I showed areas (HH in Fig. 3) with statistically significant (at the 0.05 level) cluster of high values. With more than six area units showing significant $I$ values, there is strong evidence of local clustering of high stray cat densities mainly in South Auckland particularly in Manukau City. An area to the north of Auckland was found to have an LL type of classification with surrounding areas having similarly low densities of stray cats. Areas elsewhere do not exhibit statistically significant clustering of stray cat densities for the period.
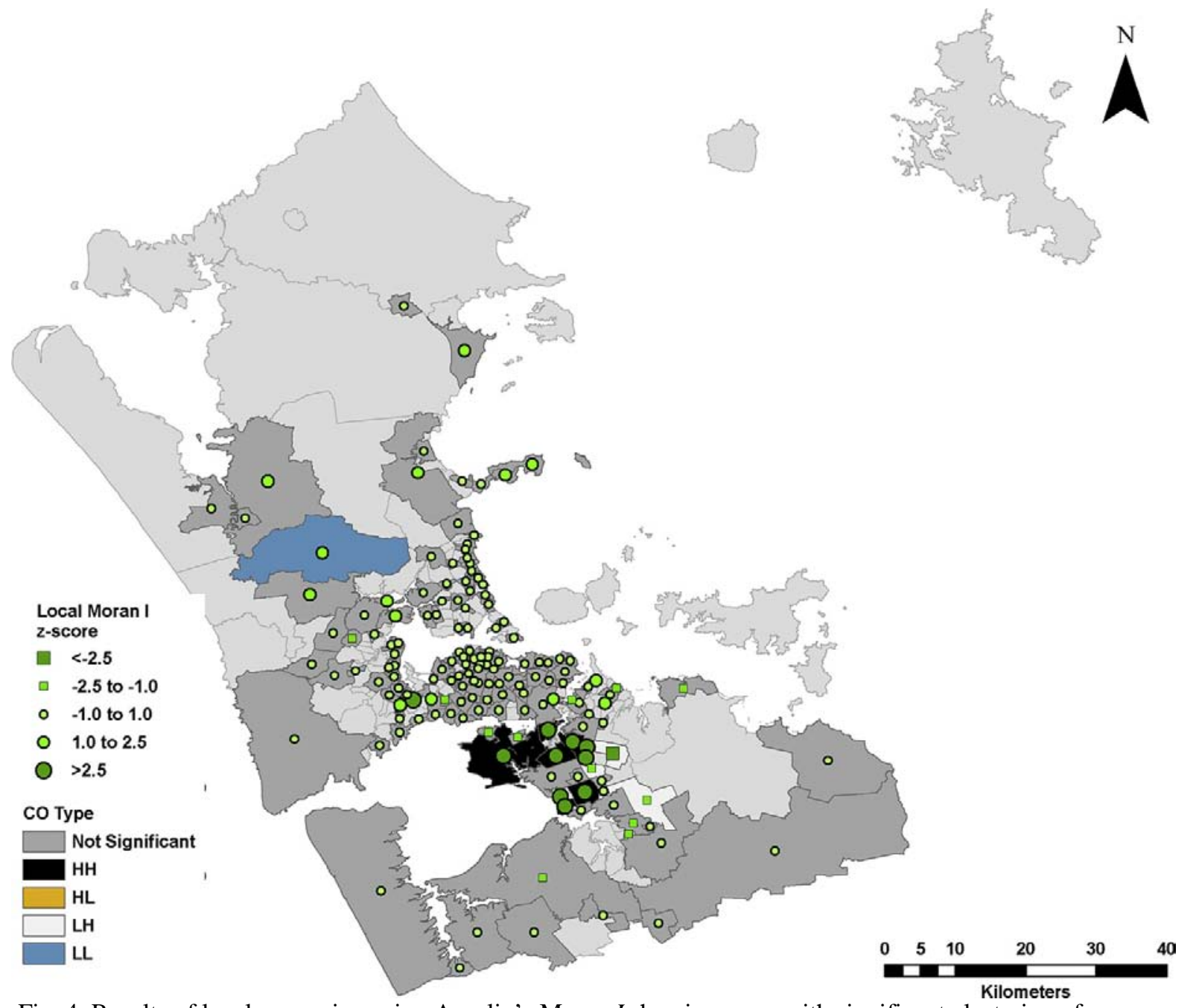

$$
\text { statistically significant clustering of stray cat densities for the period. }
$$

Fig. 4. Results of local regression using Anselin's Moran I showing areas with significant clustering of stray cat densities. 
OLS and GWR results for socioeconomic analysis

When the weighted scores of NZDep2006 for the larger city wide areas were calculated, the highest scores were in Southern Auckland, specifically Manukau City and Papakura District. Lower scores representing areas with lesser deprivation were found in the Northern areas of Rodney District and North Shore City. Results of OLS show slightly positive correlation between stray cat density and the NZ Deprivation Score of 2006 (adjusted $r^{2}=0.167$ ). When global Moran's $I$ was run using the residuals of OLS, the results do not provide evidence of spatial autocorrelation $(I=0.042$; z-score $=$ $1.209 ; p$ value $=0.226$ ).

Results of GWR (adjusted $r^{2}=0.232$ ) was consistent with the OLS results providing more support for the positive relationship between deprivation scores and stray cat density. Mapping the predicted or estimated values and the local $r^{2}$ results show that the GWR model fits better in South Auckland areas providing an indication of better predictive results than the other areas (Fig. 5). To test for spatial autocorrelation of the GWR results, the global Moran's $I$ test of the residuals showed a random distribution $(I=0.027$; $z$-score $=0.829$; $p$ value $=0.406)$ indicating the absence of misspecification in the model. OLS results show an AIC of 1105 while GWR has an AIC of 1095. With a lesser value and a difference of more than 3 in the AIC values, GWR provided more information than OLS.

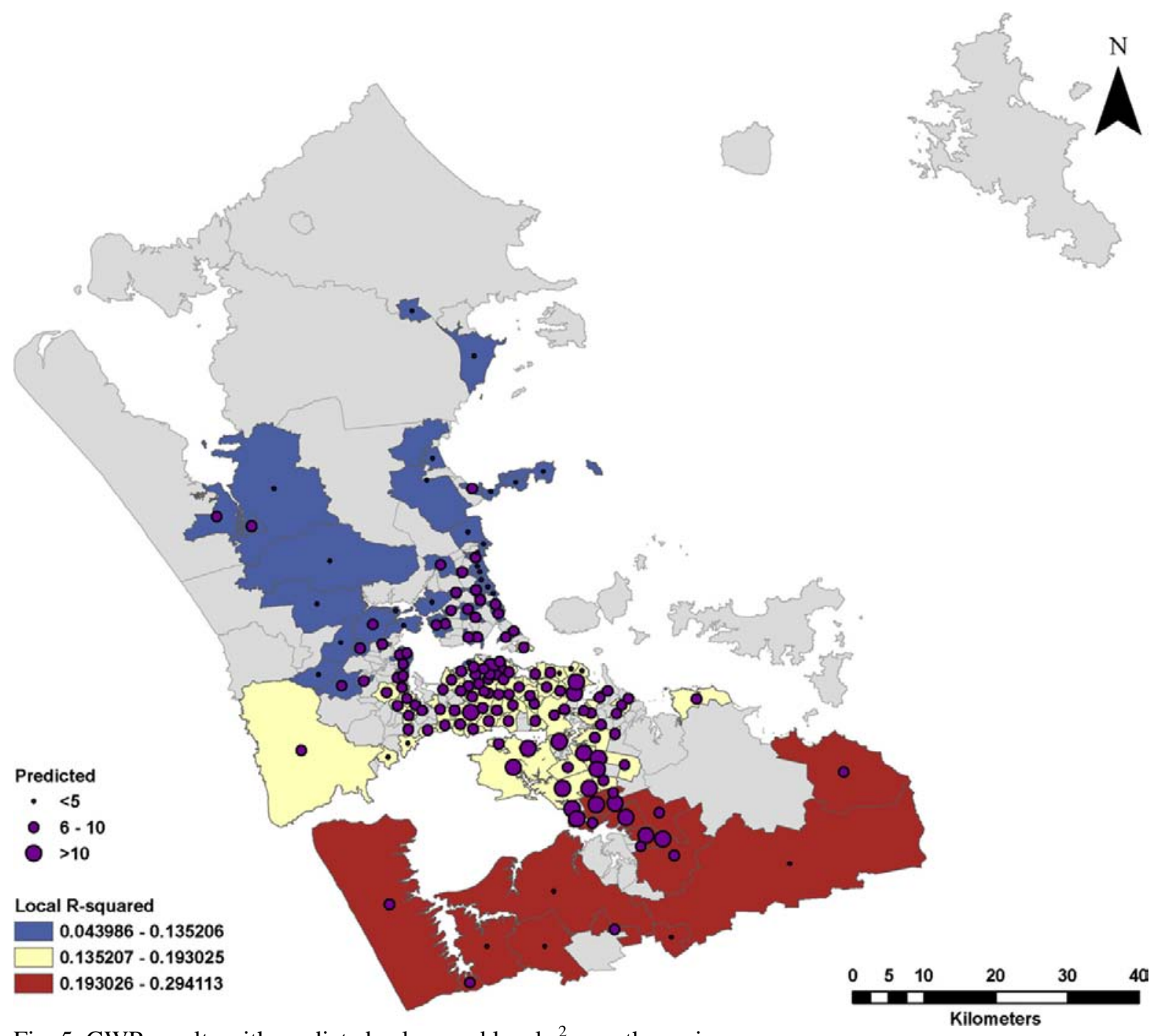

Fig. 5. GWR results with predicted values and local $r^{2}$ over the region. 


\section{Conclusions}

Transforming ordinary data sources collected by non-specialists formats suitable for GIS analysis required significant error correction using a combination of tools in the spreadsheet software. It also required direct manual correction until the majority of the data were geocoded. Most of the corrected errors consisted of incorrectly entered road types reflecting the direct entry of information into a spreadsheet without any automatic address or location checking. This shows the advantage of using a geodatabase or even just an automatic selection of predefined accurate addresses, streets, areas or other correct geographic information from the very start of data collection or record keeping. The use of GPS to record location when the stray cat is picked up the best option to avoid the efforts involved in geocoding.

The resulting data when matched with official databases and shapefiles provided the basis for area based analysis that followed. Areas with highest stray cats are in mostly in the Southern areas of Auckland with Manurewa with the highest stray cat density followed by Papakura. In terms of streets identified with most stray cat pickups, the highest are in Mangere and Manurewa providing confirmation of the area rankings.

Results of GWR show positive correlation between stray cat density and the population weighted scores of NZ Deprivation Index of 2006. The low resolution of the data means that the results of statistical analysis at this stage should only be considered as an indicator of possible relationships between presence of stray cats and social conditions. It does provide potential for the targeting of information about the care of cats and their sterilization to areas where NZDep2006 score is highest. It also suggests that informal education (e.g. school visits by welfare charities) may be best focussed in similar areas.

We recommend an increase in resolution to determine the clustering of stray cats within smaller neighbourhoods through recording the actual coordinates of pickups. This will allow better understanding of the interactions between stray cats and the anthropogenic environments in which they live. Preceding this, collation of non-specific data that can be similarly converted will be useful, particularly with regard to increasing awareness of how stray cats and socioeconomic indicators interact on a national scale. By identifying these dynamics the limited funds available to manage stray cat population, and the associated welfare problems, can be better targeted.

\section{Acknowledgements}

The data on stray cats were provided by the Auckland Society for the Prevention of Cruelty to Animals. Particular thanks go to Sarah Fuller.

\section{References}

Ahlqvist, O., Ban, H., Cressie, N., \& Shaw, N. Z. (2010). Statistical counterpoint: knowledge discovery of choreographic information using spatio-temporal analysis and visualization. Applied Geography, 30(4), 548-560.

Alessa, L., Kliskey, A., \& Brown, G. (2008). Social-ecological hotspots mapping: a spatial approach for identifying coupled social-ecological space. Landscape and Urban Planning, 85(1), 27-39.

Anselin, L. (1995). Local indicators of spatial association-LISA. Geographical Analysis, 27(2), 93-115.

Anselin, L., Syabri, I., \& Youngihn, K. (2006). GeoDa: an introduction to spatial data analysis. Geographical Analysis, 38(1), 5-22.

Argante, J. (2008). Mad about cats. North and South, 264, 60-67.

Aronsohn, M. G., \& Fagella, A. M. (1993). Surgical techniques for neutering 6- to 14-week-old kittens. Journal of the American Veterinary Medical Association, 202, 53-55.

Bradshaw, J. W. S., Horsfield, G. F., Allen, J. A., \& Robinson, I. H. (1999). Feral cats: their role in the population dynamics of Felis catus. Applied Animal Behaviour Science, 65, 273-283.

Brunsdon, C., Fotheringham, S., \& Charlton, M. (1998). Geographically weighted regression modeling spatial non-stationarity. The Statistician, 47, 431-443.

Calver, M. C., Grayson, J., Lilith, M., \& Dickman, C. R. (2011). Applying the precautionary principle to the issue of impacts by pet cats on urban wildlife. Biological Conservation, 144, 18951901.

Dark, S. J. (2004). The biogeography of invasive alien plants in California: an application of GIS and spatial regression analysis. Diversity \& Distributions, 10(1), 1-9. 
Downes, M., Canty, M. J., \& More, S. J. (2009). Demography of the pet dog and cat population on the island of Ireland and human factors influencing pet ownership. Preventive Veterinary Medicine, 92, 140-149.

Farnworth, M. J., Campbell, J., \& Adams, N. J. (2010). Public awareness in New Zealand of animal welfare legislation relating to cats. New Zealand Veterinary Journal, 58(4), 213-217.

Farnworth, M. J., Campbell, J., \& Adams, N. J. (2011). What's in a name? Perceptions of stray and feral cat welfare and control in Aotearoa New Zealand. Journal of Applied Animal Welfare Science, 14(1), 59-74.

Farnworth, M. J., Dye, N. G., \& Keown, N. (2010). The legal status of cats in New Zealand: a perspective on the welfare of companion, stray and feral domestic cats (Felis catus). Journal of Applied Animal Welfare Science, 13(2), 180-188.

Fitzgerald, B. M., \& Karl, B. J. (1986). Home range of feral cats (Felis catus) in forests of Orongorongo Valley, Wellington, New Zealand. New Zealand Journal of Ecology, 9, 71-81.

Flocks, J. G. (2004). Converting analog interpretative data to digital formats for use in database and GIS applications. Weston, VA: US Geological Survey.

Fotheringham, S. A., Brunsdon, C., \& Charlton, M. (2002). Geographically weighted regression: The analysis of spatially varying relationships. Chicester: Wiley.

Gao, J., \& Li, S. (2010). Detecting spatially non-stationary and scale-dependent relationships between urban landscape fragmentation and related factors using geographically weighted regression. Applied Geography, 31(1), 292-302.

van Heezik, Y., Smyth, A., Adams, A., \& Gordon, J. (2010). Do domestic cats impose an unsustainable harvest on urban bird populations? Biological Conservation, 143(1), 121-130.

Jones, E. (1977). Ecology of the feral cat on Macquarie Island. Australian Wildlife Research, 4, 249262.

Jones, E., \& Coman, B. J. (1982). Ecology of the feral cat in S.E. Australia. III: home ranges and population ecology in semiarid N.W. Victoria. Australian Wildlife Research, 9, 409-420.

Jung, J. K., \& Elwood, S. (2010). Extending the qualitative capabilities of GIS: computer-aided qualitative GIS. Transactions in GIS, 14(1), 63-87.

Kays, R. W., \& DeWan, A. A. (2004). Ecological impact of inside/outside house cats around a suburban nature preserve. Animal Conservation, 7, 273-283.

Kerridge, B. K. (2000). Cat position paper. Auckland: The Society for the Prevention of Cruelty to Animals.

Khormi, H., \& Kumar, L. (2011). Modeling dengue fever risk based on socioeconomic parameters, nationality and age groups: GIS and remote sensing based case study. Science of the Total Environment, 409, 4713-4719.

King, C. (1984). Immigrant killers: Introduced predators and the conservation of birds in New Zealand. Auckland, New Zealand: Oxford University Press.

Langham, N. P. E. (1992). Feral cats (Felis catus L.) on New Zealand farmland II. Seasonal activity. Wildlife Research, 19, 707-720.

Langham, N. P. E., \& Porter, R. E. R. (1991). Feral cats (Felis catus L.) on New Zealand farmland I. Seasonal activity. Wildlife Research, 18, 741-760.

Legendre, P. (1993). Spatial autocorrelation: trouble or new paradigm? Ecology, 74, 1659-1673.

Levinthal, J. (2010). The Community Context of animal and human Maltreatment: Is there a relationship between animal Maltreatment and human Maltreatment: Does Neighborhood Context Matter?. Publicly accessible Penn Dissertations. Paper 274. http://repository.upenn.edu/edissertations/274.

Liberg, O., Sandell, M., Pontier, D., \& Natoli, E. (2000). Density spatial organisation and reproductive tactics in the domestic cats and other felids. In D. C. Turner, \& P. Bateson (Eds.), The domestic cat: The biology of its behaviour (pp. 119-147). UK: Cambridge University Press.

Marino, J., Bennett, M., Cossios, D., Iriarte, A., Lucherini, M., Pliscoff, P., et al. (2011). Bioclimatic constraints to Andean cat distribution: a modelling application for rare species. Diversity and Distributions, 17(2), 311-322.

Marston, L. C., \& Bennet, P. C. (2009). Admissions of cats to animal welfare shelters in Melbourne, Australia. Journal of Applied Animal Welfare Science, 12, 189-213.

McKay, S. A., Farnworth, M. J., \& Waran, N. K. (2009). Current attitudes toward, and incidence of, sterilization of cats and dogs by caregivers (owners) in Auckland, New Zealand. Journal of Applied Animal Welfare Science, 12(4), 331-344.

Mitchell, A. (2005). The ESRI Guide to GIS analysis. In Spatial measurements and statistics, Vol. 2. Redlands, CA: ESRI Press. 
Moran, P. A. (1948). The interpretation of statistical maps. Journal of the Research Statistics Society Series B Statistical Methodology, 10, 243-251.

Moran, P. A. (1950). Notes on continuous stochastic phenomena. Biometrika, 37, 17-23.

Morgan, S. A., Hansen, C. M., Ross, J. G., Hickling, G. J., Ogilvie, S. C., \& Paterson, A. M. (2009). Urban cat (Felis catus) movement and predation activity associated with a wetland reserve in New Zealand. Wildlife Research, 36(7), 574-580.

Oberlies, N. H., Rineer, J. I., Alali, F. Q., Tawaha, K., Falkinham, J. O., III, \& Wheaton, W. D. (2009). Mapping of sample collection data: GIS tools for the natural product researcher. Phytochemistry Letters, 2(1), 1-9.

Patronek, G. J. (2010). Mapping and measuring disparities in welfare for cats across neighborhoods in a large US city. American Journal of Veterinary Research, 71(2), 161-168.

Salmond, C., Crampton, P., \& Atkinson, J. (2007). NZDep2006 index of deprivation user's manual. Wellington: Dept. Of Public Health, University of Otago.

Salmond, C., Crampton, P., King, P., \&Waldegrave, C. (2006). NZiDep: a New Zealand index of socioeconomic deprivation for individuals. Social Science \& Medicine, 62(6), 1474-1485.

Say, L., \& Pontier, D. (2004). Spacing pattern in a social group of stray cats: effects on male reproductive success. Animal Behaviour, 68(1), 175-180.

Schuurman, N., Peters, P. A., \& Oliver, L. N. (2009). Are obesity and physical activity clustered? A spatial analysis linked to residential density. Epidemiology, 17, 2202-2209.

Shaker, R., Craciun, A., \& Gradinaru, I. (2010). Relating land cover and urban patterns to aquatic ecological integrity: a spatial analysis. Geographica Technica, 1, 76-90.

Shi, H., Laurent, E. J., LeBouton, J., Racevskis, L., Hall, K. R., Donovan, M., et al. (2006). Local spatial modeling of white-tailed deer distribution. Ecological Modelling, 190(1-2), 171-189.

Simking, P., Wongnakphet, S., Stich, R. W., \& Jittapalapong, S. (2010). Detection of Babesia vogeli in stray cats of metropolitan Bangkok, Thailand. Veterinary Parasitology, 173(1-2), 70-75.

Slater, M. R., Di Nardo, A., Pediconi, O., Villa, P. D., Candeloro, L., Alessandrini, B., et al. (2008). Free-roaming dogs and cats in central Italy: public perceptions of the problem. Preventive Veterinary Medicine, 84, 27-47.

Staats, S., Wallace, H., \& Anderson, T. (2008). Reasons for companion animal guardianship (pet ownership) from two populations. Society and Animals, 16, 279-291.

Tao, C., \& Jiaqiu, W. (2008). Integrated spatio-temporal data mining for forest fire prediction. Transactions in GIS, 12(5), 591-611.

Wang, Q., Ni, J., \& Tenhunen, J. (2005). Application of a geographically-weighted regression analysis to estimate net primary production of Chinese forest ecosystems. Global Ecology and Biogeography, 14(4), 379-393.

Whyte, B. (2011). On the use of spreadsheets such as Excel for mapping. Cartographica: The International Journal for Geographic Information and Geovisualization, 46(1), 41-50.

Wilting, A., Cord, A., Hearn, A. J., Hesse, D., Mohamed, A., Traeholdt, C., et al. (2010). Modelling the species distribution of Flat-headed cats (Prionailurus planiceps), an endangered South-east Asian small Felid. PLoS ONE, 5(3), e9612.

Zhang, P., Wong, D. W., So, B. K. L., \& Lin, H. (2011). An exploratory spatial analysis of western medical services in Republican Beijing. Applied Geography, 32, 556-565. 